\title{
La progresiva adaptación del conflictivo artículo 12 de la Convención de la ONU sobre los Derechos de las personas con discapacidad en el ordenamiento jurídico español
}

\author{
The progressive adaptation of the conflictive article \\ 12 of the UN Convention on the rights of persons with \\ disabilities in Spanish legal system
}

Pedro Botello*

\section{Resumen}

El Estado Español viene implementando en nuestro ordenamiento jurídico el artículo 12 de la Convención de la ONU sobre los Derechos de las Personas con Discapacidad, a través de ciertas medidas importantes, como pueden ser el hecho de que nuestro Tribunal Supremo comience a otorgar a la curatela el papel que merece, o la reciente Ley Orgánica 1/2015 mediante la cual se anuncia la sustitución de los términos procedimiento de incapacitación e incapacitados.

Palabras claves: Discapacidad. Convención Naciones Unidas. Artículo 12. Procedimiento de incapacitación. Curatela.

\section{Abstract}

The Spanish State is implementing to our legal system the article 12 of the UN Convention on the Rights of Persons with Disabilities, trough certain important mesures, such as the fact that our Supreme Court is starting to give curatorship the role it deserves, or the recent Organic Law 1/2015 by which it is annouced the substituition of the concepts of disability and incapacitation procedure.

Keywords: Disability. United Nations Convention. Article 12. Incapacitation procedure. Guardianship. 


\section{Introducción}

La Convención de Naciones Unidas sobre los Derechos de las Personas con Discapacidad aprobada en Nueva York el 13 de Diciembre de 2006 (en adelante la Convención), es sin lugar a dudas la norma jurídica más importante jamás aprobada a nivel mundial a favor de las personas con discapacidad, como queda reflejado en los principios que la componen, que son el respeto a la dignidad inherente a la persona, la autonomía individual (incluida la libertad para tomar las propias decisiones), la independencia de cada ser humano, la no discriminación, la participación e inclusión plenas y efectivas en la sociedad, la igualdad de oportunidades, el respeto por la diferencia y la aceptación de las personas.

La Convención fue el resultado de un largo proceso en el que participaron varios actores, como Organizaciones no gubernamentales, entre las que tuvieron un papel destacado las de personas con discapacidad y sus familias, y muy señaladamente las españolas (ESPANHA, 2011) ${ }^{1}$.

Desde su ratificación por España el 23 de noviembre de $2007^{2}$, la Convención pasó a formar parte a todos los efectos de nuestro ordenamiento jurídico en virtud de lo dispuesto en los arts. 10.2 y 96.1 de la Constitución Española, y en el artículo 1.5 del Código Civil, quedando por tanto obligado el Estado Español a adaptar o modificar una serie de leyes relacionadas con el ámbito de la discapacidad hasta que la Convención quede implementada cien por cien a nuestro sistema.

Prueba de ello fue la aprobación del Real Decreto 422/2011, de 25 de Marzo, por el que se aprueba el Reglamento sobre las condiciones básicas para la participación de las personas con discapacidad en la

Así se establece en el Preámbulo de la Ley 26/2011, de 1 de agosto, de adaptación normativa a la Convención Internacional sobre los Derechos de las Personas con Discapacidad.

2 Publicada en el «Boletín Oficial del Estado» núm. 96, de 21 de Abril de 2008. Entrando definitivamente en vigor el 3 de mayo de 2.008 . 
vida política y en los procesos electorales, con idea de implementar el artículo 29 de la Convención ${ }^{3}$; o la Ley 26/2011, de 1 de agosto, de adaptación normativa a la Convención Internacional sobre los Derechos de las Personas con Discapacidad, mediante la cual se modifican una serie de Leyes en la misma línea.

Precisamente, en su Disposición Final segunda, la Ley 26/2011 recogía un mandato que obligaba al Gobierno a refundir ciertas leyes sobre discapacidad ${ }^{4}$, lo cual se acabó llevando a cabo mediante la publicación del Real Decreto Legislativo 1/2013, de 29 de noviembre, por el que se aprueba el Texto Refundido de la Ley General de derechos de las personas con discapacidad y de su inclusión social.

Aunque hay que reconocer el esfuerzo legislativo que en los últimos años está haciendo el Gobierno Español para adaptar la Convención, también lo es que la reforma legislativa más esperada por los organismos relacionados con el mundo de la discapacidad sigue sin producirse. Me refiero, como no, a la aprobación del proyecto de ley de adaptación del artículo 12 de la Convención, para que todas las personas con discapacidad puedan ejercer su capacidad jurídica (incluyéndose en ésta tanto la capacidad jurídica española como la de obrar) en igualdad de condiciones con el resto de personas. O dicho de otra forma, que se implemente el artículo de la Convención que exige que las personas con discapacidad sean apoyadas o asistidas por otra persona en aquellos actos que lo necesiten, sin que ello conlleve la privación total de su capacidad de obrar.

Por mi parte entiendo que la Convención mediante su artículo 12 lo que pretende es que dejemos de plantearnos hasta qué grado necesita

3 El art. 29 de la Convención de la ONU sobre los derechos de las personas con discapacidad dispone: «Los Estados Partes garantizarán a las personas con discapacidad los derechos políticos y la posibilidad de gozar de ellos en igualdad de condiciones con las demás».

$4 \quad$ La Ley 13/1982, de 7 de abril, de integración social de las personas con discapacidad; La Ley $51 / 2003$, de 2 de diciembre, de igualdad de oportunidades, no discriminación y accesibilidad universal de las personas con discapacidad; y la Ley 27/2007, de 23 de octubre, por la que se reconocen las lenguas de signos españolas y se regulan los medios de apoyo a la comunicación oral de las personas sordas, con discapacidad auditiva y sordociegas. 
una persona que se modifique su capacidad de obrar para realizar una vida plena en nuestra sociedad, y comencemos a verlo desde el punto de vista de que la persona con discapacidad lo que necesita son apoyos, no modificaciones en su capacidad de obrar. De ahí que la verdadera cuestión que la Convención pretende que se planteen los Estados Parte tras adaptar su artículo 12 sea la siguiente, ¿qué nivel de apoyo o asistencia necesita esa persona con discapacidad para desarrollar su vida con total normalidad e igualdad con el resto de personas?

\section{La difícil adaptación del artículo 12 de la convención ONU sobre los derechos de las personas con discapacidad}

El artículo 12 es el de mayor importancia de todos los que la componen la Convención, dado que en él se regula el hecho de que las personas con discapacidad puedan ejercer su capacidad jurídica en igualdad de condiciones que el resto de personas.

Y dentro de los cinco apartados que lo conforman, he de destacar el tercero y el cuarto por ser los que establecen que los Estados Parte, deberán adoptar todas las medidas necesarias para facilitar a las personas con discapacidad el apoyo necesario para ejercer su capacidad jurídica.

Podemos llegar a la conclusión de que el artículo 12 de la Convención dio problemas desde su propia redacción. $Y$ es que el tema de la capacidad jurídica a la que hace referencia suscitó grandes discusiones entre los Estados firmantes, llegándose incluso en algún momento a temer por la ruptura de la adopción del texto final de la Convención.

La dificultad se centraba en la distinción, ya clásica por otra parte, de capacidad jurídica y capacidad de obrar, ya que mientras algunos países defendían el pleno reconocimiento y garantía tanto de una como de otra para las personas con discapacidad, otro grupo de países abogaban por una referencia exclusivamente a la capacidad jurídica 
sin ninguna mención a la capacidad de obrar (CANTERO, 2014, p. 43), prevaleciendo finalmente esta última opción.

De ahí que la capacidad jurídica a la que hace referencia la Convención englobe tanto el concepto de capacidad jurídica de nuestro sistema como el de capacidad de obrar.

En el Derecho español se entiende por capacidad jurídica la aptitud estática del sujeto, a quien, por el mero hecho de ser persona y por su dignidad como tal, el ordenamiento jurídico le atribuye derechos y obligaciones, tanto en la esfera personal como en la patrimonial; mientras que por capacidad de obrar se entiende la aptitud de poner en movimiento por sí mismo los poderes y facultades que surgen de sus propios derechos, y en general, para desenvolverse con autonomía en la vida jurídica.

El resultado de la redacción del definitivo artículo 12 de la Convención, como mínimo, podemos calificarlo de complejo y excesivamente largo.

García Cantero (2014, p. 68) lo considera como uno de los preceptos más extensos, complejos, con alguna frecuencia difuso, en exceso quizás casuístico y hasta de los de más oscura y confusa redacción de la Convención.

En nuestro ordenamiento jurídico, cuando hablamos de apoyo o asistencia en la capacidad de obrar de las personas hacemos referencia al procedimiento de incapacitación.

Parte de nuestra doctrina más cualificada coincide con la mayoría de organismos que representan a las personas con discapacidad al entender que el procedimiento de incapacitación español es una institución contraria al espíritu de la Convención, abogando por ello por su eliminación y sustitución por otro tipo de medidas de apoyo.

Tal conclusión la alcanzan al entender que mediante la sentencia de incapacitación se priva a la persona con discapacidad de su capacidad de obrar, vulnerándose por tanto su dignidad y su derecho a la igualdad. 
Por todo ello, desde estos sectores se ha venido manteniendo que la reforma legislativa que suponga la adaptación del artículo 12 de la Convención a nuestro ordenamiento conlleve la sustitución del actual procedimiento de incapacitación español por otro diferente, del que deberá destacar un nuevo título, la eliminación de las figuras jurídicas que actualmente lo componen (la tutela, la curatela, patria potestad prorrogada, el defensor judicial, e incluso la guarda de hecho) y la introducción en nuestro sistema de nuevas medidas de apoyo a favor de las personas con discapacidad que sean más acordes a lo exigido en el artículo 12 de la Convención, tomándose siempre como ejemplo a seguir el de la figura del administrador de apoyo italiano.

Particularmente no comparto la necesidad de eliminar las instituciones jurídicas que componen el actual procedimiento de incapacitación, ya que mediante éstas se protege a las personas con discapacidad en armonía con lo exigido por la norma internacional, tal y como acreditaré en los epígrafes siguientes del presente artículo.

\section{La sentencia del tribunal supremo 421/2013, como mejor ejemplo de la implementación efectiva del artículo 12 a través de la curatela}

Parte de nuestra doctrina más autorizada, como recientemente expone Gabriel Cantero (2014, p. 93), considera que la sentencia de mayor valor jurídico dictada por nuestro Tribunal Supremo sobre la adaptación del artículo 12 de la Convención a nuestro ordenamiento interno hasta que el Poder Legislativo no cumpla con su deber de adaptación, es la sentencia 282/2009 de 29 de Abril de 2009.

Particularmente discrepo rotundamente de dicho razonamiento. En mi opinión, la sentencia más importante de nuestro Alto Tribunal al respecto es, sin ningún género de dudas, la sentencia 421/2013, de 24 de junio de 2.013 .

Para explicar mi razonamiento comenzaré centrándome en el contenido de la sentencia 282/2009 de 29 de Abril de 2009, para acabar 
el presente epígrafe centrándome en el alcance de la importantísima sentencia de junio de 2.013 .

En cuanto a la sentencia 282/2009 de abril de 2.009, coincido con dicha corriente doctrinal en considerarla como ejemplo más importante de la compatibilidad existente entre nuestro actual procedimiento de incapacitación y el espíritu de la Convención en general, ya que, me permito reiterar, el procedimiento de incapacitación español conlleva una serie de medidas de protección a favor de las personas con discapacidad que lo hacen compatible con lo exigido en la Convención.

Dicho esto, lo que no considero posible es poner como ejemplo de adaptación del artículo 12 de la Convención a nuestro ordenamiento a través del procedimiento de incapacitación a la referida sentencia, ya que en la misma se siguió declarando incapaz en modo absoluto y permanente para regir su persona y sus bienes a la persona con discapacidad enjuiciada, yendo tal decisión contra el espíritu de la Convención en cuanto al ejercicio de la capacidad de obrar de las personas con discapacidad.

Particularmente entiendo que en base a la Convención, el medio de protección que dicha persona necesitaba era el nombramiento de un curador que le asistiese o apoyase en determinados actos concretos, y no su incapacitación absoluta. De hecho, a tal conclusión llego en base a las afirmaciones que se hacen en la sentencia, como por ejemplo:

a) El Juez de Primera Instancia para incapacitar a la señora expuso: "sólo cabe limitarla en los supuestos como el que nos ocupa porque Doña V., por sí sola, le es imposible participar libremente en los distintos aspectos de la vida, personales (vestir, pasear, etc.), familiares (llevar la casa, comprar, etc.), o sociales (visitas relaciones etc.) -no puede estar presente en estas actuaciones- e incluso aquellas otras que vienen impuestas por la administración del patrimonio que posee (ha conferido poder general), por lo que necesita protección, vigilancia o representación de otras personas, que sustituyan o complementen aquella cualidad o estado de la que carece...". 
Pero, ¿cuál de los supuestos arriba mencionados conlleva la necesidad de privar a una persona totalmente de su capacidad de obrar? ¿Tal vez haber otorgado un poder? ¿No poder comprar, llevar la casa o recibir visitas?

Tomar cualquiera de estas razones como motivo para nombrar un tutor que rija de modo absoluto la persona y sus bienes, considero que puede entenderse contrario el espíritu de la Convención.

b) El mismo juez tras su inspección personal a la señora, recogió: "Se trata de una persona de avanzada edad, afectada por una enfermedad visible de Parkinson, que se orienta bien en el tiempo y en el espacio, conoce sus circunstancias personales, a su familia y a su entorno, pudiendo afirmar que puede realizar actos propios de la vida cotidiana, no así complejos como sería la administración de sus bienes".

¿Acaso no parece claro que lo que necesitaba la persona en cuestión era un curador que le apoyase únicamente en su ámbito patrimonial?

c) A todo esto hay que sumarle el contenido del informe del médico forense que actuó en primera instancia, el cual reflejó que: "aunque los diagnósticos de las enfermedades que padece no son incapacitantes por sí mismos...ante la complejidad de sus bienes, y ante la situación socio-familiar, podría llevarle a sufrir engaños por terceras personas...".

Es decir, que el médico forense entendía que los diagnósticos de las enfermedades que padecía la señora no eran incapacitantes por sí mismos, pero que sí podía sufrir ésta engaños por terceras personas.

Entonces, ¿por qué no se le designó un curador para todos los actos patrimoniales, en vez de un tutor para todo su ámbito personal y patrimonial?

En base a todo lo anterior, entiendo que la Sentencia 282/2009, de 29 de Abril de 2009, no es la sentencia que mejor refleja la idoneidad de la adaptación del artículo 12 de la Convención a nuestro ordenamiento jurídico. 
En cambio, la Sentencia 421/2013, de 24 de junio de 2.013, fue la primera en considerar el nombramiento de un curador a favor de la persona con discapacidad como medio idóneo de adaptación del artículo 12 de la Convención, a lo que hay que sumarle el interés casacional de la misma, con las consecuencias jurídicas que ello conlleva para el resto de los Tribunales españoles.

En este supuesto, la Sentencia de primera instancia declaró incapacitado al demandado, tanto para regir su persona y bienes, incluida la privación del derecho activo, como su patrimonio, y nombró tutor a una entidad pública.

El demandado interpuso recurso de apelación que fue desestimado, como también fue desestimada la solicitud del Ministerio Fiscal de que fuera sometido a curatela, interesado en la vista celebrada en la alzada, "porque las limitaciones que padece el demandado exigen acudir a la curatela".

La Sentencia fue recurrida en casación tanto el demandado como el propio Ministerio Fiscal, citando como infringida la Convención sobre los Derechos de las Personas con Discapacidad, firmada en Nueva York el 13 de diciembre de 2006, ratificada por España el 23 de noviembre de 2007, y los artículos 199 , 200 y 287 del Código Civil, puestos en relación con los artículos 10, 14, 23 y 96 de la Constitución Española. Considera que existe una clara desproporcionalidad en la medida adoptada en la Sentencia, lo que también comparte el Ministerio Fiscal, una vez practicada la prueba en segunda instancia, por lo que solicitó la instauración de una curatela, ya que en los informes periciales no hablan de limitación total, único caso en el que procedería la incapacitación total, que es la que, finalmente, se ha adoptado en contra de la proporcionalidad y adaptación a las circunstancias de la persona exigidas ambas por el artículo 12 del Convenio, privándole, incluso, de derechos fundamentales, como el de sufragio, cuando no existe ninguna referencia a la supuesta pérdida de las habilidades para que se vea privado del derecho de voto, o incluso, de la posibilidad de gobernarse 
por sí mismo, cuando siempre lo ha hecho para atender sus propios asuntos.

El Tribunal Supremo casó la sentencia, con las consecuencias jurídicas que ello conlleva para el futuro de este tipo de procedimientos.

El Fallo de la Sentencia es en mi opinión, el claro ejemplo de que por un lado las medidas tuitivas existentes en nuestro actual procedimiento de incapacitación son suficientes para llevar a cabo la adaptación del artículo 12 de la Convención a nuestro ordenamiento interno, y por otro lado, refleja que apostando por la curatela como medio de apoyo de las personas con discapacidad tanto en su ámbito personal como en el patrimonial, tal y como pretendía la Ley 13/198, de 24 de octubre de reforma de la tutela, no hace falta incluir ninguna medida de apoyo nueva a favor de este sector de la sociedad española. Literalmente expone el Fallo en su punto $2^{\circ}$ :

Declarar que Don Camilo es parcialmente incapaz tanto en el aspecto personal como patrimonial, la cual será complementada por un curador. En la esfera personal requerirá la intervención del curador en cuanto al manejo de los medicamentos prescritos, ayuda de su enfermedad y autocuidado, el cual decidirá en su caso la permanencia en residencia o su internamiento en un establecimiento de salud mental o de educación o formación especial. En lo que se refiere al patrimonio y economía, conservará su iniciativa pero precisará del curador para su administración, gestión y disposición, ya sea inter vivos o mortis causa, completando su incapacidad. Controlará y fiscalizará todos sus gastos, incluidos los corrientes, evitando el gasto excesivo y la manipulación por parte de terceras personas, sin perjuicio de que se le asigne una suma periódica para su consumo y necesidades cotidianas de la vida (dinero de bolsillo).

Aunque la enorme importancia práctica de la Sentencia 421/2013 no sólo se refleja en la elección de la curatela como medio de protección ideal tanto en el ámbito patrimonial como personal, de la persona con discapacidad psíquica, sino que también destaca por su posicionamiento relativo al sufragio pasivo de la persona a incapacitar, ya que establece 
al respecto que en ningún caso queda afectado el derecho de sufragio del que se le privó sin justificación alguna en las otras instancias.

El artículo 29 de la Convención garantiza a las personas con discapacidad los derechos políticos y la posibilidad de gozar de ellos en igualdad de condiciones y como corolario lógico ejercer el derecho de voto que se considera conveniente y beneficioso, mientras que el artículo 3.1 b y 2 de la Ley 5/85, de 19 de julio, del Régimen Electoral General, señala que los declarados incapaces en virtud de sentencia judicial firme quedarán privados del derecho de sufragio, siempre que la misma declare expresamente la incapacidad para su ejercicio, debiendo los Jueces o Tribunales que entiendan de los procedimientos de incapacitación o internamiento pronunciarse expresamente sobre la incapacidad para el ejercicio del sufragio. La pérdida del derecho de sufragio no es una consecuencia automática o necesaria de la incapacidad, sino que son compatibles la incapacitación y la reserva al incapaz de este derecho, ya que una cosa es que la persona no pueda regirse por sí misma, ni administrar su patrimonio, y otra distinta es que esa persona esté impedida para ejercitar correctamente su derecho al voto.

Es el Juez que conoce del proceso a quien corresponde analizar y valorar la situación de la persona sometida a su consideración y pronunciarse sobre la conveniencia de negar el ejercicio de este derecho fundamental. En la sentencia nada se argumenta en cuanto a que no pueda hacerlo, o que no pueda discernir el sentido de su voto, o que lo ponga en riesgo mediante la actuación de terceros, antes al contrario, su habilidad para tomar una decisión de esta clase no ha sido cuestionada y parece además conveniente que así lo haga de forma libre, como medida terapéutica para el tratamiento de su enfermedad, que puede verse afectada por el rechazo que deriva de su estado.

A modo de conclusión entiendo fundamental dejar expuesto que el mayor reflejo de la enorme importancia de la sentencia comentada, se aprecia en su interés casacional y las consecuencias jurídicas que ello conlleva para el resto de nuestros Tribunales, ya que debido al Fallo 
de la misma éstos quedan obligados a establecer siempre la curatela en vez de la tutela como medio de protección o asistencia a favor de la persona que lo necesite.

De hecho, desde la publicación de la Sentencia 421/2013, de 24 de junio de 2.013, se han dictado más de 300 sentencias de Audiencias Provinciales ${ }^{5}$ en términos casi idénticos respecto a la del Supremo, en el sentido establecer un curador como medio de protección idóneo a favor de la persona con discapacidad, en vez de un tutor tal y como se venía adoptando hasta entonces casi por defecto.

De dichas sentencias entiendo interesante destacar algunas por su contenido, dado que en ellas en primera instancia se estableció un tutor a favor de la persona con discapacidad, siendo sin embargo revocada esta decisión por la Audiencia al considerarse que en base al espíritu de la Convención, y al posicionamiento del Supremo al respecto, el medio ideal de protección para la persona con discapacidad era el nombramiento de un curador, y no el de un tutor.

Así por ejemplo se recoge en la SAP de Barcelona 712/2014, de 29 de octubre, 2014, en la cual se revoca una sentencia de primera instancia en la que se había establecido un tutor para proteger a una persona con trastorno mental por consumo de alcohol y rasgos inmaduros de personalidad, para acabar nombrándole un tutor.

La curatela de los incapacitados se concibe en términos más flexibles, para incapacitaciones parciales, en las que la sentencia gradúa el alcance de la incapacidad, y consecuentemente determina la competencia del órgano tutelar; no se circunscribe expresamente la curatela a la asistencia en la esfera patrimonial, por lo que podría

5 Entre otras, las Sentencias de AP de Pontevedra, núm. 362/2014, de 6 noviembre; SAP de Barcelona, núm. 770/2014, de 19 de noviembre; SAP de A Coruña, núm. 406/2014, de 25 noviembre; SAP de Barcelona, núm. 794/2014, de 2 diciembre; SAP de Asturias, núm. 321/2014, de 9 diciembre; SAP de León, núm. 272/2014, de 15 de diciembre; SAP de Barcelona, núm. 851/2014, de 17 diciembre; SAP de Barcelona, núm. 860/2014, de 18 diciembre; SAP de Barcelona, núm. 863/2014, de 18 diciembre; SAP de Tarragona, núm. 2/2015, de 2 de enero; SAP de Asturias, núm. 20/2015, de 22 enero; SAP de Huesca, núm. 8/2015, de 29 enero. 
atribuirse al curador funciones asistenciales en la esfera personal, como pudiera ser la supervisión del sometimiento del incapaz a un tratamiento médico, muy adecuado cuando carece de conciencia de enfermedad; de modo que el curador no suple la voluntad del afectado, sino que la refuerza, controla y encauza, complementando su deficiente capacidad, por lo que su función no viene a ser de representación, sino más bien de asistencia y protección en el concurso que presta su apoyo e intervención para aquellos actos que haya de realizar el incapaz y estén especificados en la sentencia, los que no tienen que ser específicamente de naturaleza patrimonial (si la sentencia de incapacitación no hubiese especificado los actos en que deba ser necesaria la intervención del curador se entenderá que ésta se extiende a los mismos actos en que los tutores necesitan autorización judicial).

Mientras que la SAP de Álava 310/2014, de 4 de diciembre ${ }^{6}$ expone que:

Frente a la sentencia recurrida, que declara la discapacidad de la apelante disponiendo el nombramiento de tutor, se alza la afectada considerando que la prueba no lo justifica, entendiendo más acorde a sus circunstancias la adopción de un régimen de curatela. (...). En este caso la prueba evidencia que la situación de la Sra. Virginia no obliga a constituir tutela. Todos los testimonios coinciden en que para los actos de su vida cotidiana puede valerse por sí misma, aunque necesite alguna supervisión. (...). Por todo ello la prueba practicada en la vista permite llegar a la conclusión de que efectivamente se debe declarar una discapacidad parcial, conforme al art. $287 \mathrm{CCv}$, limitada a las cuestiones de índole económica que excedan de los gastos de bolsillo, así como para asegurar el sometimiento al tratamiento médico, manteniéndose el pronunciamiento de la sentencia de instancia respecto de la persona del curador, que será la Fundación Tutelar Bero [...].

6 RJ 2015, 62059. 


\section{La sustitución del título del procedimiento de incapacitación y del término incapacitado en la reciente ley orgánica 1/2015 de reforma del código penal}

Tal y como vengo argumentando a lo largo del presente trabajo, el título del actual procedimiento de incapacitación no es acorde al espíritu de la Convención.

Por ello vengo abogando por otro título que anuncie a las personas que van a iniciarlo (o a sus familiares) que una vez obtengan la sentencia correspondiente podrán ser considerados frente a la sociedad como una persona que necesita el apoyo de otra para realizar ciertas actividades (como al fin y al cabo nos sucede a todos en algún ámbito de la vida, o nos sucederá), dejando por tanto atrás el antiguo estigma que suponía el convertirse en una persona no capaz (incapacitado) que conllevaba la sentencia de incapacitación.

En este sentido el Gobierno Español al año siguiente de la entrada en vigor de la Convención en nuestro país, a través de la Ley 1/2009, de 25 de marzo $^{7}$, concretamente mediante su Disposición Final Primera, se obligaba a:

remitir a las Cortes Generales en el plazo máximo de seis meses un proyecto de ley reguladora de los procedimientos de incapacitación judicial, que pasarán a denominarse procedimientos de modificación de la capacidad de obrar, para su adaptación a las previsiones de la Convención.

Como nos tiene acostumbrado nuestro legislador en los últimos tiempos, la Disposición Final Primera únicamente sirvió para reflejar las buenas intenciones de éste, si bien el contenido de la misma jamás se llevó a efecto.

Ley $1 / 2009$, de 25 de marzo, de reforma de la Ley de 8 de junio de 1957, sobre el Registro Civil, en materia de incapacitación, cargos tutelares y administradores de patrimonios. (ESPANHA, 2009) 
Cuatro años después, concretamente el 5 de julio de 2010, ve la luz en la página web del Consejo General del Poder Judicial Español, el documento de trabajo elaborado por el Ministerio de Justicia sobre la posible reforma del Código civil, del Estatuto Orgánico del Ministerio Fiscal y de la Ley 1/2000 de Enjuiciamiento Civil en materia de modificación judicial de la capacidad y de las medidas de protección y apoyo de menores y de personas con capacidad modificada judicialmente, en el cual se dirigen al procedimiento de incapacitación como "modificación judicial de la capacidad", y al incapacitado como "persona con capacidad modificada judicialmente".

Sin embargo, lo cierto es que dicho documento expresa sólo unas líneas generales a desarrollar, a modo de borrador de anteproyecto de ley, por lo que no se le puede conceder importancia práctica alguna más allá de mencionarla.

El verdadero paso al frente en cuanto a la sustitución de los términos "procedimiento de incapacitación" e "incapacitado" se ha producido muy recientemente mediante la Ley Orgánica $1 / 2015$, de 30 de marzo ${ }^{8}$, por la que se modifica la Ley Orgánica 10/1995, de 23 de noviembre, del Código Penal, y que entrará en vigor a partir del próximo 1 de julio del presente año. A partir de dicha fecha, en nuestro Código Penal se hará referencia al incapacitado como "persona con discapacidad necesitada de una especial protección", y al procedimiento de incapacitación como "procedimiento de modificación de la capacidad"10.

Dicho lo cual, lo cierto es que en la actualidad el título del procedimiento sigue siendo el mismo en todos los ámbitos de nuestro ordenamiento jurídico, por lo que nos referimos a éste en el resto del trabajo como procedimiento de incapacitación.

Pero llegados a este momento hemos de cuestionarnos, ¿acertó el legislador en los términos elegidos para sustituir los tan mencionados de incapacitados e incapacitación?

\footnotetext{
8 Publicada en el BOE de 31 de marzo de 2015 (ESPANHA, 2015).

9 Tal y como se desprende del apartado XXVII de su Preámbulo.

10 Como establece la Disposición adicional primera.
} 
Vayamos por parte. El primer término que usa es el de "persona con discapacidad necesitada de una especial protección" para sustituir el término de incapacitado.

En el apartado quince de su artículo único, recoge la referida Ley Orgánica 1/2015, de 30 de marzo, que

\begin{abstract}
A los efectos de este Código se entiende por discapacidad aquella situación en que se encuentra una persona con deficiencias físicas, mentales, intelectuales o sensoriales de carácter permanente que, al interactuar con diversas barreras, puedan limitar o impedir su participación plena y efectiva en la sociedad, en igualdad de condiciones con las demás.Asimismo a los efectos de este Código, se entenderá por persona con discapacidad necesitada de especial protección a aquella persona con discapacidad que, tenga o no judicialmente modificada su capacidad de obrar, requiera de asistencia o apoyo para el ejercicio de su capacidad jurídica y para la toma de decisiones respecto de su persona, de sus derechos o intereses a causa de sus deficiencias intelectuales o mentales de carácter permanente.
\end{abstract}

¡Ojo! Habla la nueva ley siempre de persona con discapacidad como beneficiaria, con las consecuencias que ello puede suponer, tal y como expondré a continuación.

De dicho artículo se desprende que la prioridad del legislador ha sido ampliar la protección del Código Penal no sólo a las personas que ostentasen la condición de incapacitadas, sino a todas las personas con discapacidad intelectual o mental en general aún sin haber sido incapacitadas.

Sin duda, intención loable la del legislador de proteger a todas las personas con discapacidad, pero particularmente considero que debido a la redacción dada en la nueva ley podemos encontrarnos con un vacío legal de importantes consecuencias jurídicas, como es el siguiente: ¿Qué sucederá, en cambio, con las personas que teniendo reconocida su incapacidad judicialmente no tengan acreditada ninguna discapacidad? 
En base a la literalidad del artículo mencionada la respuesta parece muy clara: No quedarían protegidos en el nuevo Código Penal, aún estando legalmente incapacitados.

Por mi parte encuentro a este importante problema que podría llegar a plantearse una posible solución acudiendo a la vía civil.

La nueva Disposición Adicional que añadió a nuestro Código civil la Ley 41/2003 ${ }^{11}$, de 18 de noviembre, de Protección Patrimonial de las Personas con Discapacidad, en adelante LPPD, supuso la introducción en nuestro sistema civil por primera vez del término "discapacidad", al recoger que:

La referencia que a personas con discapacidad se realiza en los arts. 756, 822 y 1041, se entenderá hecha al concepto definido en la Ley de protección patrimonial de las personas con discapacidad y de modificación del Código civil, de la Ley de Enjuiciamiento Civil y de la normativa tributaria con esta finalidad.

Establece el art. 2.3 de la LPPD que:

Personas con discapacidad son las afectadas por una minusvalía psíquica igual o superior al treinta y tres por ciento o por una minusvalía física o sensorial igual o superior al sesenta y cinco por ciento, grado de minusvalía que se deberá acreditar, en uno u otro caso, mediante certificado expedido conforme a lo establecido reglamentariamente o por resolución judicial firme.

Observando la definición de persona con discapacidad se llega a la conclusión de que el grado de discapacidad podrá acreditarse de dos formas diferentes:

I- Certificado expedido conforme a lo establecido reglamentariamente

11 Ley 41/2003, de 18 de noviembre, de protección patrimonial de las personas con discapacidad, y de modificación del Código Civil, de la Ley de Enjuiciamiento Civil y de la Normativa Tributaria con esta finalidad. Fue publicada en el B.O.E. de 19 noviembre de 2003. (ESPANHA, 2003) 
Para obtener el certificado de discapacidad han de seguirse los pasos establecidos en el Real Decreto 1971/1999, de 23 de diciembre, de procedimiento para el reconocimiento, declaración y calificación del grado de discapacidad ${ }^{12}$. Dicho RD vio modificado su título en su última palabra, minusvalía, introduciéndose la que hoy aparece, discapacidad, mediante el Real Decreto 1856/2009, de 4 de diciembre, de procedimiento para el reconocimiento, declaración y calificación del grado de discapacidad.

En esta norma queda regulado no sólo el procedimiento que hay que seguir para que se reconozca el grado de discapacidad, sino también los baremos aplicables así como los órganos competentes para su reconocimiento.

II- Resolución judicial firme.

En cuanto a la resolución judicial firme, el legislador no se pronuncia en cuanto a qué resolución judicial se refiere. ¿Qué quiere ello decir?

Una vez estudiado el RD1971/1999, se aprecia que, si bien no existe intervención del juez en ningún momento del procedimiento, las resoluciones en las que se reconozca el grado de discapacidad podrán ser recurridas, primero en vía administrativa, y, posteriormente, en vía judicial. Sin embargo, la jurisdicción competente para recurrir la resolución administrativa es la social ${ }^{13}$, a diferencia de la jurisdicción a

12 RD.1971/1999, de 23 de diciembre sobre el procedimiento para el reconocimiento, declaración y calificación del grado de discapacidad (BOE núm. 22, de 26 de Enero de 2000), posteriormente modificado por el RD. 1169/2003, de 12 de septiembre (BOE núm. 238, de 4 de octubre), por la Disp. Fin. $3^{a}$ del RD. 290/2004, de 20 de Febrero, por el que se regulan los enclaves laborales como medida de fomento del empleo de las personas con discapacidad (BOE núm. 45, de 21 de Febrero), por el RD. 504/2007, de 20 de abril, por el que se aprueba el baremo de valoración de la situación de dependencia establecido por la Ley 39/2006, de 14 de diciembre, de promoción de la autonomía personal y atención a las personas en situación de dependencia (BOE núm. 96, de 21 de abril) que deroga el Anexo 2 y por el RD 1856/2009, de 4 de diciembre (BOE núm. 311, de 26 de diciembre), que modifica tanto su título como su contenido en cuanto a la sustitución del término minusvalía por el de discapacidad.

13 Establece el art. 12 del RD. 1971/1999: <<Contra las resoluciones definitivas que sobre reconocimiento de grado de minusvalía se dicten por los organismos competentes, los interesados podrán interponer reclamación previa a la vía jurisdiccional social de conformidad con lo establecido en el art.71 del texto refundido de la Ley de Procedimiento Laboral, aprobado por el Real Decreto Legislativo 2/1995, de 7 de abril>>. 
la que se acude cuando se quiere incapacitar a una persona, que es la civil.

Entonces, ¿por qué no hace referencia expresa el art. 2.3 de la LPPD a que la resolución judicial firme provendrá siempre del orden jurisdiccional social?

¿Por qué reza literalmente en dicho artículo que el grado de discapacidad se deberá acreditar, en uno u otro caso, mediante certificado expedido conforme a lo establecido reglamentariamente o "por resolución judicial firme", sin especificar si la resolución judicial debe ser del orden jurisdiccional social o civil?

En mi opinión, el legislador no fijó en la LPPD exclusivamente la resolución judicial del orden social como única vía para acreditar la discapacidad, por un único motivo: Para que la resolución judicial de incapacitación de la vía civil conlleve también automáticamente el reconocimiento de persona con discapacidad.

De admitirse tal posibilidad, estaríamos afirmando que cualquier persona incapacitada con anterioridad a la entrada en vigor de la Ley Orgánica 1/2015, de modificación del Código Penal, formaría parte de las denominadas "personas con discapacidad necesitadas de especial protección", aún cuando no tenga la condición de persona con discapacidad reconocida, salvando con ello el problema que antes planteaba. Pero, ¿en qué me baso para otorgar a la sentencia de incapacitación la misma validez que a la resolución administrativa de discapacidad?

Estaríamos afirmando que el legislador equipara las personas incapacitadas judicialmente con las que sufran algún tipo de discapacidad, sin necesidad de ningún tipo de resolución administrativa. Y yo me pregunto, ¿y acaso no sería esto lo lógico?

Pues principalmente en base a los siguientes argumentos:

$1^{\circ}$ Para que una persona sea incapacitada tiene que padecer una enfermedad mental persistente que le impida gobernarse por sí misma, por lo que una persona que haya sido incapacitada judicialmente por su 
discapacidad psíquica siempre se encontrará afectada, como mínimo, por el grado del 33\% que exige la LPPD para considerarla una persona con discapacidad psíquica.

O dicho de otra forma, toda persona incapacitada judicialmente tendrá como mínimo un grado de discapacidad psíquica del $33 \%$, aunque no lo tenga acreditado mediante resolución administrativa porque jamás lo hubiese intentado.

$2^{\circ}$ Por otra parte, la falta de equiparación supondría el sin sentido de que las medidas de protección de la LPPD no beneficiasen a la persona incapacitada, sino sólo a las personas con discapacidad, lo cual podría llevar a una serie de consecuencias, bajo mi punto de vista, un tanto rocambolescas, como por ejemplo, la defendida por Pereña Vicente ${ }^{14}$, de que los incapacitados no podrán disfrutar del patrimonio protegido que se puede crear a favor de una persona con discapacidad, o a favor de una persona incapacitada judicialmente que sí tenga el grado de discapacidad reconocido administrativamente ${ }^{15}$ (arts. del 1 al 8 de la propia LPPD). ¿Sería lógico que a favor de la persona con discapacidad que ha sido incapacitada judicialmente sí pueda constituirse un patrimonio protegido, y no pueda en cambio constituirse este mismo patrimonio protegido a favor de la persona incapacitada judicialmente

14 PEREÑA VICENTE, "Asistencia y protección de las personas incapaces o con discapacidad: Las soluciones del Derecho Civil”, Dykinson, Madrid, 2006, págs. $53,54,55$ y 56 , la cual, centrándose en la medida de protección del patrimonio protegido, acaba confesando que "éste es uno de los principales problemas de la Ley, que no ofrece el mismo grado de protección a los incapacitados judiciales y a los discapacitados. (...) Con toda seguridad, en la mayor parte de los supuestos en los que una persona está judicialmente incapacitada su grado de minusvalía será igual o superior al exigido por la Ley para constituir el patrimonio protegido, pero la sentencia de incapacitación, como hemos visto en el Capítulo I, no será suficiente para proceder a su constitución".

15 Estipula, en primer lugar, la Exposición de Motivos de la LPPD, en su apartado III que: <<Esta constitución del patrimonio corresponde a la propia persona con discapacidad que vaya a ser beneficiaria del mismo o, en caso de que ésta no tenga capacidad de obrar suficiente, a sus padres, tutores o curadores de acuerdo con los mecanismos generales de sustitución de la capacidad de obrar regulados por nuestro ordenamiento jurídico... >>. En el mismo sentido, recoge el art. 3.1.b) que: <<Podrán constituir un patrimonio protegido: Sus padres, tutores o curadores cuando la persona con discapacidad no tenga capacidad de obrar suficiente>>. Entendemos que, al nombrar a los tutores o curadores de las personas que no tengan capacidad de obrar suficiente, se está refiriendo a personas que hayan sido judicialmente incapacitadas, ya que es ésta la única forma legal de que se nombre un tutor o curador a favor de la persona que lo necesita. 
que no haya pasado por el procedimiento administrativo para obtener resolución que fije su grado de discapacidad?

Otra de las medidas introducías por la LPPD a favor de las personas con discapacidad-incapacitadas es el de la nueva causa de indignidad que afecta a los familiares de éstas que no le prestaren las atenciones necesarias durante su vida (arts. 10.1 de la LPPD y 756.7 C.c.). De ahí que de no otorgársele el mismo alcance a la sentencia de incapacitación que a la resolución administrativa de discapacidad, los familiares de las personas incapacitadas judicialmente que no le hubiesen prestado a ésta en vida las atenciones debidas no se verían afectados por las nuevas causas de indignidad sucesoria que sí afectan a los familiares de una persona con discapacidad ${ }^{16}$ a la que no tampoco le hubiesen prestado la atención necesaria. ¿Parece esto razonable?

E igualmente creo falto de lógica no entender sujetos a colación los gastos realizados por los padres y ascendientes para cubrir las necesidades especiales de sus hijos o descendientes con discapacidad (art. $1041.2^{\circ}$ C.c.), y en cambio que sí quedasen sujetos a colación los gastos realizados a favor del hijo incapacitado por sus padres y ascendientes.

Como último ejemplo de los supuestos introducidos por la LPPD que, en mi opinión, debe favorecer indistintamente a persona con discapacidad e incapacitada, me refiero a la donación o el legado de un derecho de habitación sobre la vivienda habitual que su titular haga a favor de una persona con discapacidad, los cuales no se computarán para el cálculo de las legítimas si en el momento del fallecimiento ambos estuvieren conviviendo en ella. Este derecho de habitación se atribuirá por ministerio de la ley en las mismas condiciones al legitimario con discapacidad que lo necesite y que estuviera conviviendo con el

\footnotetext{
16 Mientras que en el art. 10.1 de la LPPD sí se concretiza que: $<<$ Tratándose de una persona con discapacidad, las personas con derecho a la herencia que no le hubieran prestado... >>, no ocurre lo mismo en la Exposición de Motivos, apartado VII de la misma Ley, donde se recoge que: $<<$ Se configura como causa de indignidad generadora de incapacidad para suceder abintestato el no haber prestado al causante las atenciones debidas durante su vida...".No especifica que se trate de una persona con discapacidad, sino que habla del causante, por lo que podría entenderse bien la persona con discapacidad bien la persona incapacitada judicialmente.
} 
fallecido, a menos que el testador hubiera dispuesto otra cosa o lo hubiera excluido expresamente, pero su titular no podrá impedir que continúen conviviendo los demás legitimarios mientras lo necesiten (art. 822 C.c.).

\section{¿Tendría sentido que el derecho al que se refieren los 2 párrafos} anteriores no se pueda aplicar igualmente a las personas incapacitadas judicialmente?

$3^{\circ}$.- Por último, porque equiparar directamente a las personas incapacitadas judicialmente con las personas con discapacidad, aunque aquéllas no hubiesen obtenido la resolución administrativa que así lo acreditase, es una postura defendida ya por diversos autores ${ }^{17} \mathrm{y}$ sentencias ${ }^{18}$.

17 VIVAS TESÓN, La dignidad de las personas con discapacidad. Logros y retos jurídicos, Difusión Jurídica, Madrid, 2.010, pág. 55, considera que "Otra opción podría ser considerar innecesario que la persona incapacitada judicialmente deba tramitar la obtención de su certificado de discapacidad al reconocérsele ésta automáticamente. (...) Así las cosas, creemos que el legislador debería recoger expresamente, a los efectos del Derecho civil, la equiparación entre incapacitación judicial y discapacidad". RUIZ-RICO RUIZ MORON, "La reforma del Derecho de Sucesiones...", Op.cit. pág. 359 entiende por su parte que "Mientras que todo incapacitado va a ser persona con discapacidad, no se puede hacer, sin embargo, la afirmación inversa". DÍAZ ALABART, "Principios de protección jurídica del discapacitado", en Protección Jurídica y patrimonial de los discapacitados, BELLO JANEIRO, D. (coord.), Escola Galega de Administración Pública, Santiago de Compostela, 2004, pág. 99, argumenta que "Es más, de la Exposición de Motivos de esta norma parece deducirse que el concepto de discapacitado pretende dejarse al margen de la incapacitación, como si ambas regulaciones transcurriesen absolutamente paralelas, lo cual es de todo punto imposible, puesto que los incapaces desde el punto de vista jurídico necesariamente deben ser considerados discapacitados, si bien todos los discapacitados no siempre serán incapaces, porque aquél es un concepto más amplio que éste". Continúa la autora DÍAZ ALABART, S., et alii: La protección jurídica de las personas con discapacidad: (estudios de la Ley 41/2003, de protección patrimonial de las personas con discapacidad), Ibertuamur y Associació Catalana Naibu, 2004, , exponiendo que "no presenta ningún problema que a los incapacitados judicialmente se les considere "discapacitados" en el sentido de la LPPD (...). A pesar de dicho silencio, como ya hemos señalado con anterioridad, todo incapacitado es un discapacitado, (pero no viceversa), por lo que podrá ser beneficiario de la protección patrimonial que otorga esta Ley". Y en el mismo sentido, NÚÑEZ NÚÑEZ, "Diversos aspectos sucesorios introducidos por la Ley 41/2003 de 18 de Noviembre, a favor de las personas discapacitadas", en La Encrucijada de la incapacitación y la discapacidad, Director: José Pérez de Vargas Muñoz, Coordinación: Montserrat Pereña Vicente, La Ley, Madrid, 2011, pág. 963, quien afirma que en la práctica, todos los judicialmente incapacitados son discapacitados psíquicos, de manera que muchas veces las dos situaciones van juntas, si bien la Ley 41/2003 contiene normas que se aplican únicamente a uno de los dos supuestos.

18 V. SAP de Cádiz (Sección $2^{\mathrm{a}}$ ), de 21 de marzo de 2005 (JUR 2005/144287), en la cual se equiparan las figuras de personas con discapacidad y de incapacitado, <<sea cual sea el régimen peculiar del patrimonio de éste, puesto que, en suma, estaríamos discriminando desfavorablemente a los discapacitados o incapacitados cuyos guardadores, tutores o ejercientes de la curatela no 


\section{Reformas necesarias en el, todavía, procedimiento de incapacitación actual}

Concluyendo con el presente trabajo, entiendo oportuno dejar expuesto que si bien la figura de la curatela es el medio de adaptación ideal del artículo 12 de la Convención a nuestro ordenamiento jurídico, también considero obligatorio que el futuro proyecto de ley de adaptación del artículo 12 deberá reflejar una serie de modificaciones en nuestro actual procedimiento de incapacitación.

Así que llegado a este punto, me permito hacer de predictor en relación con las posibles modificaciones que introducirá el próximo proyecto de ley. Aún siendo consciente de que el ejercicio de predicción siempre es arriesgado y con un alto índice de posibilidades de fallar en las predicciones, considero que el proyecto de ley de adaptación del artículo 12 a nuestro ordenamiento interno supondrá, entre otras, las siguientes modificaciones en el actual procedimiento de incapacitación:

I. Regulación legal del carácter preferencial de la curatela frente a la tutela

Bajo mi punto de vista, la modificación más importante, ya que mediante la misma los jueces españoles quedarían obligados a nombrar en todo momento a un curador en los actos que la persona lo necesitase, quedando reservado el nombramiento de un tutor a los casos en los que, debido al nivel de la imposibilidad de autogobierno de la persona, fuese la única solución.

Aunque, tal y como acabamos de exponer, parece que desde la Sentencia del Tribunal Supremo No 421/2013, de 24 de junio de 2013, las Audiencias Provinciales de forma pacífica comienzan a pronunciarse en dicho sentido, considero necesario el establecimiento como regla

hubieran adoptado las medidas precisas para la constitución del patrimonio separado a que se refiere la Ley 41/2003, sin que en nada difiera la naturaleza y fundamento de la venta de bienes de personas discapacitadas de la de los bienes de personas judicialmente incapacitadas, de modo que, si para aquéllas es beneficioso el que se prescinda de la pública subasta en la enajenación de sus bienes, también habrá de serlo para éstas >>. 
general de la curatela como medio de protección idóneo a favor de las personas que necesiten apoyo o asistencia, otorgando un carácter residual a la posibilidad de nombrar tutores a favor de las personas con necesidad de protección.

Al mismo tiempo, siempre desde el punto de vista de una nueva regulación más completa de la curatela, considero que el artículo 290 del Código civil debe quedar derogado ya que, según éste, "si la sentencia de incapacitación no hubiese especificado los actos en que deba ser necesaria la intervención del curador, se entenderá que ésta se extiende a los mismos actos en que los tutores necesitan, según este Código, autorización judicial". Tal y como vengo afirmando a lo largo del presente trabajo, considero que el juzgador deberá quedar obligado a establecer con precisión y de modo exhaustivo los actos y contratos por los que el declarado incapaz necesitará de asistencia.

II. Adoptar todas las medidas necesarias para agilizar el procedimiento

Aquí sí tomamos como ejemplo el sistema italiano, en el que desde que una persona solicita al juzgado un administrador de apoyo hasta que el juez lo nombra pueden pasar un máximo de 60 días, mientras que en España, los procedimientos de incapacitación oscilan entre año y año y medio, como mínimo.

III. Creación de Juzgados especializados en la materia y formación de sus profesionales, así como de todos los actores implicados

La nueva Ley ha de implementar en nuestro sistema Juzgados específicos de la materia, como existen por ejemplo los de violencia de género, así como una formación específica de todos los funcionarios (Fiscales, Médicos Forenses, Oficiales, Trabajadores Sociales...), tal y como recomendó el Comité sobre los Derechos de las Personas con Discapacidad de las Naciones Unidas mediante la observación número 34 de septiembre de 2011. Con ello se conseguiría, en primer lugar, que los procedimientos fuesen mucho más rápido. Pero sobre todo, y lo que es más importante, se conseguiría que especialistas en la materia 
valorasen el grado específico de apoyo o asistencia que cada persona necesita individualmente.

$\mathrm{E}$, igualmente, sería de gran importancia que se exigiese una formación obligatoria para aquellas personas que ejerzan o vayan a ejercer cargos tutelares fuera del ámbito de la tutela familiar, como, por ejemplo, se introdujo en Francia mediante la Ley de 5 de marzo de 2007.

$Y$ es que, de seguir las mismas estructuras que regulan el actual sistema de incapacitación (jueces sobrecargados de trabajo y sin especialización en la materia, así como fiscales, médicos de forenses etc., en el mismo sentido), por mucho que se refuerce la curatela, ésta fracasaría, tal y como lo hizo en el sistema vigente tras la reforma del Código Civil mediante la Ley 13/1983 en el mismo sentido.

IV. Obligación de los jueces de fijar en la Sentencia revisiones y evaluaciones periódicas de la persona a la que se le haya asignado un curador-tutor cada cierto tiempo.

Hemos de tener en cuenta que el grado de enfermedad que suponga el nombramiento de un curador (también, pero menos, en el caso de enfermedades que supongan el nombramiento de un tutor) a favor de una persona con discapacidad puede aumentar o disminuir de forma considerable en el tiempo dependiendo de diversos factores (tratamiento, edad..), por lo que entendemos necesario se fijen en la sentencia de incapacitación los plazos en los que ha de llevarse a cabo una revisión del estado de salud del curatelado para ver si subsiste, o ha aumentado o disminuido la necesidad de apoyo o asistencia que éste necesitaba en el momento de la sentencia.

V. Automático reconocimiento de la discapacidad administrativa tras la Sentencia de incapacitación, bien sea total o parcial

No tiene sentido que en la actualidad, la sentencia de incapacitación no lleve implícita el reconocimiento a una discapacidad administrativa, ya que por ejemplo, debido a ello, las medidas de protección patrimonial introducidas por la LPPD a favor de las personas con discapacidad 
(como la constitución a su favor de un patrimonio protegido) no podrán aplicarse a una persona incapacitada mediante sentencia judicial firme.

Lo que defiendo es que el contenido del artículo 72.1 del RD $439 / 2007^{19}$ de 30 de Marzo por el que se considera acreditado un grado de discapacidad igual o superior al $65 \%$ cuando se trate de personas cuya incapacidad sea declarada judicialmente aunque no haya alcanzado dicho grado mediante resolución administrativa, debería darse en todas las ramas jurídicas de nuestro ordenamiento.

De este modo, cualquier persona que haya sido incapacitada judicialmente quedará englobada en el concepto "persona con discapacidad necesitada de una especial protección" que el nuevo Código Penal usará para definir a los incapacitados a partir del próximo 1 de julio de 2015.

\section{Conclusiones}

Poco a poco parece que el legislador español se viene decantando por implementar el conflictivo artículo 12 de la Convención ONU a nuestro ordenamiento mediante una serie de adaptaciones y modificaciones de diversas normas, en vez de aprobar el tan anunciado proyecto de ley de adaptación normativa del ordenamiento jurídico para dar cumplimiento al artículo 12 de la Convención.

Lo cierto es que la adaptación definitiva del artículo de la Convención de mayor trascendencia jurídica sigue a día de hoy sin producirse. Me refiero, como no puede ser de otra forma, a la adaptación del artículo 12 de la Convención, la cual obliga a los Estados Partes a que las personas con discapacidad puedan ejercer su capacidad jurídica (la

19 Real Decreto 439/2007, de 30 de marzo, por el que se aprueba el Reglamento del Impuesto sobre la Renta de las Personas Físicas y se modifica el Reglamento de Planes y Fondos de Pensiones, aprobado por Real Decreto 304/2004, de 20 de febrero, Publicado en el BOE núm. 78, de 31 de Marzo de 2007. (ESPANHA, 2007) 
capacidad jurídica de la Convención engloba tanto la capacidad jurídica como la capacidad de obrar española) en igualdad de condiciones que el resto de personas, es decir, que todas las personas con discapacidad que lo necesiten, se vean apoyadas o asistidas por otra persona sin que en ningún caso les sea por ello privada su capacidad jurídica ni su capacidad de obrar.

Primero fue con el reconocimiento de nuestro Tribunal Supremo mediante la sentencia 282/2009 de 29 de Abril de 2009, de la compatibilidad existente entre nuestro procedimiento de incapacitación y la Convención de la ONU, descartando con ello nuestro Alto Tribunal cualquier necesidad de sustituir dicho procedimiento por otro que se base en más apoyos a favor de las personas que los necesiten.

Años más tarde, a raíz de la sentencia 421/2013, de 24 de junio de 2.013, el Tribunal Supremo fija la curatela como el medio idóneo de adaptación del artículo 12 de la Convención, sentencia que en la actualidad, y debido a su interés casacional, siguen todas las Audiencias Provinciales Españolas.

Y el último de los pasos dados por el legislador para que el artículo 12 de la Convención quede implementado definitivamente en nuestro ordenamiento jurídico es el de la sustitución de los términos procedimiento de incapacitación e incapacitado por los de modificación de la capacidad y persona con discapacidad necesitada de una especial protección. ¿Acierta con la inclusión del concepto persona con discapacidad en el nuevo término? Bajo mi punto de vista no. Es más, considero que va a conllevar a ciertas confusiones en nuestra sociedad, que esperemos salve de forma rápida con la aclaración de las dudas planteadas en el presente estudio, el cual concluyo lanzando una pregunta al aire: ¿Por qué el legislador de 2015 no aprovechó la ocasión para disipar cualquier duda equiparando directamente la sentencia de incapacitación con la resolución administrativa que acredita la condición de discapacidad de una persona? 


\section{Referencias}

ESPANHA. Lei 26/2011. Adaptación normativa a la Convención Internacional sobre los Derechos de las Personas con Discapacidad. 2011. Disponível em: <https://www.boe.es/diario_boe/txt. php?id=BOE-A-2011-13241>. Acesso em: 03 set. 2014

CANTERO, Gabriel García. ¿Persons with disability vs. personas incapacitadas... o viceversa? Inserción del art. 12 del Convenio de Nueva York de 2006, en el Ordenamiento español. Revista de Derecho Civil, Madrid, v. 1, n. 4, p. 67-106, out./dez. 2014.

ESPANHA. Ley 1/2009. Reforma de la Ley de 8 de junio de 1957, sobre el Registro Civil, en materia de incapacitaciones, cargos tutelares y administradores de patrimonios protegidos, y de la Ley 41/2003, de 18 de noviembre, sobre protección patrimonial de las personas con discapacidad y de modificación del Código Civil, de la Ley de Enjuiciamiento Civil de la normativa tributaria con esta finalidad. 2009. Disponível em: <https://www.boe.es/boe/dias/2009/03/26/pdfs/ BOE-A-2009-5028.pdf>. Acesso em: 15 ago. 2014.

ESPANHA. Ley Orgánica 1/2015. Por la que se modifica la Ley Orgánica 10/1995, de 23 de noviembre, del Código Penal. 2015. Disponivel em: <https://www.boe.es/diario_boe/txt. php?id=BOE-A-2015-3439>. Acesso: 20 ago. 2014.

ESPANHA. Ley 41/2003. Protección patrimonial de las personas con discapacidad y de modificación del Código Civil, de la Ley de Enjuiciamiento Civil y de la Normativa Tributaria con esta finalidad. 2003. Disponível em: <https://www.boe.es/diario_boe/txt. php?id=BOE-A-2003-21053>. Acesso em: 11 set. 2014.

ESPANHA. Real Decreto 439/2007. se aprueba el Reglamento del Impuesto sobre la Renta de las Personas Físicas y se modifica el Reglamento de Planes y Fondos de Pensiones, aprobado por Real Decreto 304/2004, de 20 de febrero. 2007. Disponível em: <https:// www.boe.es/buscar/act.php?id=BOE-A-2007-6820>. Acesso em 14 set. 2014. 
ESPANHA. Lei 26/2011. Adaptación normativa a la Convención Internacional sobre los Derechos de las Personas con Discapacidad. 2011. Disponível em: <https://www.boe.es/diario_boe/txt. php?id=BOE-A-2011-13241>. Acesso em: 03 set. 2014.

CANTERO, Gabriel García. ¿Persons with disability vs. personas incapacitadas... o viceversa? Inserción del art. 12 del Convenio de Nueva York de 2006, en el Ordenamiento español. Revista de Derecho Civil, Madrid, v. 1, n. 4, p. 67-106, out./dez. 2014.

ESPANHA. Ley 1/2009. Reforma de la Ley de 8 de junio de 1957, sobre el Registro Civil, en materia de incapacitaciones, cargos tutelares y administradores de patrimonios protegidos, y de la Ley $41 / 2003$, de 18 de noviembre, sobre protección patrimonial de las personas con discapacidad y de modificación del Código Civil, de la Ley de Enjuiciamiento Civil de la normativa tributaria con esta finalidad. 2009. Disponível em: <https://www.boe.es/boe/dias/2009/03/26/pdfs/ BOE-A-2009-5028.pdf>. Acesso em: 15 ago. 2014.

ESPANHA. Ley Orgánica 1/2015. Por la que se modifica la Ley Orgánica 10/1995, de 23 de noviembre, del Código Penal.

2015. Disponível em: <https://www.boe.es/diario_boe/txt. php?id=BOE-A-2015-3439>. Acesso: 20 ago. 2014.

ESPANHA. Ley 41/2003. Protección patrimonial de las personas con discapacidad y de modificación del Código Civil, de la Ley de Enjuiciamiento Civil y de la Normativa Tributaria con esta finalidad. 2003. Disponível em: <https://www.boe.es/diario_boe/txt. php?id=BOE-A-2003-21053>. Acesso em: 11 set. 2014.

ESPANHA. Real Decreto 439/2007. Se aprueba el Reglamento del Impuesto sobre la Renta de las Personas Físicas y se modifica el Reglamento de Planes y Fondos de Pensiones, aprobado por Real Decreto 304/2004, de 20 de febrero. 2007. Disponível em: <https:// www.boe.es/buscar/act.php?id=BOE-A-2007-6820>. Acesso em: 14 set. 2014.

Recebido em: 26/06/2015

Aprovado em: 09/11/2015 